\title{
STRATEGI PEMILIHAN CHANNEL PENJUALAN SEBAGAI IMPLEMENTASI DALAM MODEL AFILIASI BISNIS PENGELOLAAN HOTEL NON JARINGAN DI KOTA BATAM
}

\author{
Desrini Ningsih ${ }^{1}$ Putu Hari Kurniawan ${ }^{2}$ \\ ${ }^{1}$ Prodi Manajemen Universitas Putera Batam \\ ${ }^{2}$ Prodi Akuntansi Universitas Putera Batam \\ Jl. R.Soeprapto,Muka Kuning, Batam \\ jimupb@gmail.com
}

\begin{abstract}
ABSTRAK
Tujuan penelitian ini adalah untuk mengkaji pemasaran hotel yang memiliki afiliasi dengan agen travel online dalam mendistribusikan layanan kamar pada tamu hotel.Dalam melaksanakan operasinya hotel dapat menggunakan media sosial untuk melakukan aktivitas promosi. Dengan melakukan strategi pemasaran ini hotel akan mendapatkan sorotan lebih baik dari pengguna sebab berdasarkan jumlah pengguna online travel dengan bantuan social media merupakan yang paling tinggi di asia tenggara hingga saat in .Tentunya dalam pelaksanaannya menggunakan direct channel sebagai role model bisnis, peran agensi travel online memediasi pemesanan kamar dengan promosi harga dengan margin profit yang menguntungkan bagi kedua belah pihak. Dalam pelaksanannya online travel agen memiliki resiko ketika tidak mampu menjual paketnya pada calon pengunjung hotel. Kami menggunakan model explanatory research kuantitatif dengan menggunakan accidental sampling pada 60 hotel non jaringan di Batam digunakan sebagai responden yang tersebar di 1 wilayah ekonomi yang potensial yaitu Nagoya. Hasil yang didapat dari dua variabel pendukung yaitu Promosi, Afiliasi Marketing dan Okupansi bisnis menunjukkan hasil yang positif. hasil pengujian menunjukkan bahwa promosi hotel non jaringan dan affiliasi bisnis dari agen travel online memainkan peranan penting dalam proses penilaian penjualan kamar hotel. Pihak hotel dan online travel berafiliasi secara terpusat dimana lebih cenderung memiliki tugas lebih komplek daripada pihak internal hotel.meskipun dalam hubungan bisnis pihak online travel lebih banyak memiliki keuntungan dari program afiliasi yang telah berjalan. Sampai saat ini hasil menunjukkan bahwa model bisnis afiliasi memiliki efek kuat terkait dengan masa depan industri perhotelan di masa mendatang.
\end{abstract}

Kata Kunci: Promosi; Affiliasi marketing; Okupansi bisnis

\section{PENDAHULUAN}

Pada waktu tertentu setiap hotel pernah mengalami kelesuan dalam memberikan pelayanan pada konsumen.Dalam beberapa moment hotel pasti mengalami penurunan pendapatan dalam penjualan yang disebabkan oleh kondisi market yang tidak
menentu.Bisnis hotel merupakan salah satu bisnis jasa yang seringkali mengalami fluktuasi dalam permintaan pasar yang lebih mengedepankan pelayanan prima pada setiap kamar yang ditawarkan. Hotel dalam satu tahun akan mengalami low peak period dimana kondisi terendah hotel tersebut dalam menjaring tamu mengalami 
penurunan karena tidak ada momen yang special dalam hitungan kalender. Pada umumnya jika terjadi keadaan seperti ini tindakan yang dilakukan adalah menurunkan harga kamar dengan alasan agar okupansi kamar dapat terlaksana dengan baik. Sebenarnya tindakan ini akan membawa kerugian terkait dengan income dan tentunya hal ini kurang baik bagi operasional hotel untuk ke depan. Menurunkan harga tidak menjamin bahwa permintaan konsumen terhadap kamar akan meningkat alih-alih hanya atas dasar meningkatkan pendapatan hotel dalam jangka pendek. Menurunkan harga tidak menjamin permintaan konsumen akan meningkat namun hanya sebagai problem solving dalam memenuhi kekurangan pendapatan.

Akhir akhir ini peran serta media sosial telah menjadi bagian yang tak terpisahkan dari kehidupan modern saat ini. Dalam melaksanakan operasinya hotel dapat menggunakan media sosial untuk melakukan aktivitas promosi. Dengan melakukan strategi pemasaran ini hotel akan mendapatkan sorotan lebih baik dari pengguna sebab berdasarkan jumlah pengguna online travel dengan bantuan social media merupakan yang paling tinggi di asia tenggara hingga saat ini. asumsi (De
Pelsmacker, van Tilburg, \& Holthof, 2018) dengan bekerjasama dengan online travel agent maka hotel yang beroperasi khususnya non jaringan dapat menyampaikan pesan terkait dengan promosi lebih luas lagi dan dapat meminimalisir biaya iklan tiap bulannya sehingga biaya operasional hotel tidak membengkak. Dengan melakukan kerjasama dengan online travel agency dapat memberikan arahan strategi hotel jika dalam keadaan low season untuk meningkatkan income dan okupansi hotel dalam jangka panjang.

\section{KAJIAN PUSTAKA}

\section{Direct Channel}

Menurut (Murphy, 2010) direct channel adalah bentuk penyaluran barang-barang ataupun jasa dari produsen kepada konsumen dengan melalui perantara. Bentuk saluran distribusi langsung bisa dibagi ke dalam empat macam yaitu antara lain selling at the point production, selling at the producer retail store dan selling trough mail. Di lain sisi (Brutu \& Mihai, 2012) menyatakan bahwa direct selling adalah metode penjualan barang dan jasa tertentu kepada konsumen dengan cara tatap muka di luar lokasi eceran tetapi tetap masih ada afiliasi dengan jaringan pemasaran yang dikembangkan oleh mitra usaha dan bekerja berdasarkan komisi penjualan. 
Menurut (Koeppelb, 2016) saluran distribusi atau direct channel merupakan sumber daya ekternal untuk membangun system internal perusahaan terkait dengan produksi, riset, rekayasa dan personil penjualan dalam menyokong fasilitas suatu perusahaan dalam operasionalisasi di lapangan. System ini mengambarkan komitmen signifikansi perusahaan terhadap sejumlah besar perusahaan independent yang bisnisnya distribusi terhadap pasar yang mereka layani.System distribusi menggambarkan komitmen terhadap seperangkat kebijakan dan praktek yang didasarkan pada pada susunan hubungan dalam jangka Panjang. (Goldstein, 2014) mengatakan arus pergerakan barang dari produsen ke konsumen harus sesuai dengan tujuannya.Suatu perusahaan harus berpedoman pada prinsip yang berkaitan dengan pelaksanaan saluran distribusi. Menurut (Kotler Philip, 2016) bentuk saluran distribusi digunakan untuk menyalurkan pelayanan jasa seperti saluran nol tingkat atau direct channel terdiri dari seorang produsen jasa yang menjual produknya ke konsumen akhir. Cara utama pemasaran langsung yaitu pemesanan lewat surat, telepon, email dan website yang dimiliki produsen atau pihak yang memiliki afiliasi dengan perusahan yang bersangkutan.

Pendapat yang berbeda tentang direct channel dalam pemasaran jasa maupun industri (Content Marketing Institute \& Direct Marketing Association (DMA) UK, 2015) memberikan arahan produsen jasa \& industri dalam prakteknya minimal dapat menggunakan tenaga penjual untuk menjual langsung ke konsumennya. Mereka dapat menjual ke distributor atau pihak ke 2 untuk kepentingan dan cabangnya sendiri langsung ke sasaran konsumen.Faktor pasar merupakan hal yang paling penting dalam mempengaruhi saluran distribusi dengan dasar pertimbangan kepuasan konsumen.Kebiasaan pembelian pelanggan jasa sangat berbeda dengan konsumen di bidang manufaktur.Kadang kala konsumen harus sesekali mendapatkan kejutan dengan peningkatan pelayanan atau pemberian diskon pada layanannya.

Menurut (Washington State Department of Agriculture, 2014) mengkategorikan landasan bisnis direct selling terdiri dari 3 hal yaitu merekrut,mendidik dan memotivasi mitra usaha. Hal ini lazim disebut distributor dimana ketiga pendukung tersebut harus mendapatkan value yang pantas sesuai dengan karakter yang diperoleh. Direct 
selling yang baik harus disesuaikan dengan kode etik tertentu sebagai alat untuk memajukan kompetisi yang sehat dan citra umum dari kegiatan bisnis pada umumnya.

\section{Affiliate marketing}

Affiliate marketing adalah bisnis yang sangat besar melalui jaringan internet yang muncul awal sejak dioperasionalisasikan sistem jaringan ke masyarakat sipil awal tahun 80- 90 an. Menurut (Eapen, Jihye, \& George, 2017) Secara umum affiliate marketing adalah suatu cara dimana kita menjualkan produk orang lain dan akan mendapatkan komisi jika terjadi pembelian melalui referensi kita. Atas dasar tersebut pemasar jasa tidak perlu memikirkan stok atau persediaan tetapi yang kita pikirkan adalah hanya mengarahkan pengunjung ke website melalui link khusus yang pemasar miliki. Link ini akan kita dapatkan dari merchant yang diberikan kepada kita sebagai alat untuk mendeteksi bahwa pembeli yang datang adalah melalui referensi kita.

(Chandra, Chao, \& Astolpho, 2014)Menyatakan Affiliate business adalah bisnis yang sangat besar di internet. Banyak sekali pebisnis online yang focus di model affiliate marketing baik pemula ataupun yang sudah expert. Bagaimana tidak,konsumen tidak perlu repot membuat produk yang spesifik tetapi komisi yang kita terima jika terjadi proses transaksi biasanya bisa mencapai $50 \%$ dari harga yang ditetapkan oleh pihak pertama. Hingga saat ini banyak pebisnis online yang mampu menghasilkan ribuan transaksi dalam kegiatannya.(Eapen et al., 2017) Memberikan pendapat bisnis affiliate tidak hanya untuk mereka yang sudah mahir di bisnis online, namun juga direkomendasikan untuk kalangan pemula. Hal ini terjadi karena bisnis afiliasi adalah kegiatan yang relatif tidak susah dilakukan yaitu tanpa membuat produk pemasar sudah bisa mengasah kemampuan penjualan di media social maupun media internet.

Dalam affiliate marketing pemasar dituntut untuk mampu mendatangkan calon pembeli ke website merchant. Dengan cara apapun anda harus mampu mendatangkan banyak calon pembeli dimana jika pemasar mendatangkan banyak calon pembeli maka jika pemasar sudah berpengalaman dan tahu cara mendatangkan traffic tersebut maka pemasar pasti akan menguasai kunci dari bisnis online secara berkesinambungan (Decker, Calo, \& Weer, 2012).

\section{Teori Agency Model}

Perspektif teori agensi merupakan dasar yang digunakan untuk memahami isu 
corporate governance dan earning management dalam prakteknya teori agensi mengakibatkan hubungan yang asimetri antara pemilik dan pengelola usaha.Untuk menghindari terjadinya hubungan yang asimetri tersebut dibutuhkan suatu konsep good corporate governance yang bertujuan untuk menjadikan perusahaan menjadi lebih sehat. Penerapan ini berdasarkan teori agensi (Shepter, 2015) yang menyatakan bahwa hubungan antara manajemen dengan pemilik fungsi agensi perperan secara bertanggung jawab untuk mengoptimalkan keuntungan secara principal dansebagai imbalannya akan memperoleh kompensasi yang sesuai dengan kontrak kedua pihak yang berkepentingan.

Masalah keagenan (agency problem) pada awalnya dieksplorasi oleh (Carroll \& Takayama, 2014) dalam kajiannya menyebutkan bahwa manager suatu perusahaan sebagai agen dan pemegang principal mendelegasikan pengambilan keputusan bisnis kepada manager yang merupakan perwakilan atau agen dari perusahaan jasa yang bersangkutan. Kajian ini didukung oleh pendapat (Johnson, 2017) manajemen laba yang didasarkan adanya teori agensi memberikan asumsi bahwa setiap individu cenderung untuk memaksimalkan utilitasnya. Konsep agensi teori memiliki hubungan secara prisipal dengan agen. Pihak pertama sebagai principal memiliki kewenangan dalam rangka memenuhi kebutuhan principal terkait dengan profit margin perusahaan dimasa yang akan datang.

(Withagen, Araújo, \& de Poel, 2017) menyatakan salah satu asumsi utama dari teori keagenan bahwa tujuan principal dan tujuan agen memiliki kebutuhan yang berbeda.Seringkali hal ini mengakibatkan konflik karena perusahaan sebagai principal cenderung untuk mengejar keinginan pribadi, sehingga hal ini dapat mengakibatkan kecenderungan perusahaan lebih fokus pada visi untuk memaksimalkan kesejahteraan perusahaan tanpa menghiraukan keuntungan jangka pendek versus memaksimalkan kesejahteraan pemilik perusahaan tersebut.

\section{Hotel Network}

(Ehtiyar \& Yildiz, 2012) menyatakan dalam prakteknya terdapat 2 kepemilikan hotel yang dihubungkan dengan pengelolaannya yaitu hotel independent dan chain hotel atau biasa disebut hotel berjaringan. Independent hotel pada umumnya tidak memiliki hubungan kepemilikan atau pada pengelolaannnya tidak berinduk pada perusahaan lain. Hal ini biasanya dimiliki oleh keluarga dan dikelola 
tanpa mengikuti prosedur maupun pengoperasian tertentu dari orang lain. Walaupun kebanyakan hotel jenis ini adalah hotel besar maupun kecil yang memiliki predikat disandang baik skala nasional maupun internasional. Biasanya merupakan satu bidang usaha lain yang dikembangkan dalam perusahaan besar dengan bisnis utama (core bisnis) berbeda yang dikelola secara professional.

Menurut (Kim, Lim, \& Brymer, 2015) hotel berjaringan adalah usaha perhotelan yang tidak berdiri sendiri dengan ciri khas bahwa hotel ini memiliki hubungan dalam kepemilikan dan cara pengelolaannya dengan perusahaan lainnya. Bentuk kerjasama ini ada empat macam yaitu perusahaan induk, berdasar pada kontrak manajemen, waralaba, dan referral group. Dalam hal ini manajemen hotel memisahkan antara kepemilikan dan pengelolaaanya dimana pemilik hotel membeli jasa pengelolaan dari perusahaan lain dengan membayar sejumlah uang sesuai dengan perjanjian sebelumnya.

Menurut (Oppenheim, 2018) hotel independen tidak memiliki cabang atau bahkan sama sekali serta tidak terikat dengan berbagai jenis bisnis property lainnya. Hotel dengan model ini biasanya merupakan bisnis keluarga namun tidak menutup kemungkinan hotel seperti ini bisa berkembang menjadi chain hotel management.

\section{METODE PENELITIAN}

Metode analisis dalam penelitian ini digambarkan hubungan yang akan dianalisis dan pengaruh hubungan antara Observed variabel dan Manifest variabel. Metode pengumpulan data yang akan dipakai adalah dengan menyebarkan langsung kepada responden. Teknik sampling yang digunakan dalam penelitian ini adalah Accidental Sampling dimana pengambilan sampel dilakukan secara tiba-tiba, sehingga seluruh anggota populasi bisa diminta informasi dan wawancara secara langsung. Hal ini dilakukan agar tidak mengganggu aktivitas responden dimana responden memiliki kesempatan yang sama untuk dijadikan sampel. Sesuai dengan model analisis yang telah dijelaskan di atas maka pengolahan dan analisis data dilakukan dengan menggunakan teknik Multivariat Structure Equation Model (SEM).

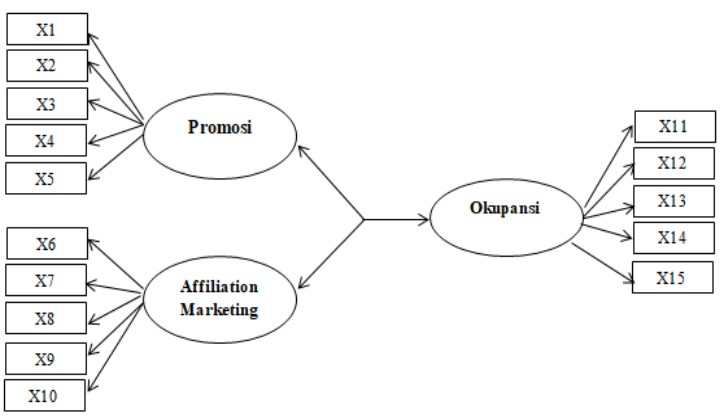

Gambar.1 Manifested Variabel 


\section{HASIL DAN PEMBAHASAN}

Jumlah kuesioner yang disebarkan sebanyak 126 eksemplar, setelah terjun ke lapangan jumlah yang dikembalikan hanya 6 orang yang mengisi tidak lengkap sehingga Dalam penelitian ini jumlah reponden yang memenuhi syarat untuk dianalisis sejumlah 120 dan jumlah seluruh variabel manifest adalah 16 sedankan rule of thumb untuk perbandingan jumlah sampel terhadap jumlah indikator adalah 1:5 (Kurniawan, Loekito, \& Solimun, 2016). Jadi jika indikator dalam penelitian ini sebanyak 16 maka minimal sampel yang dibutuhkan adalah minimal 80.(Ghozali, 2011) mengemukakan bahwa jumlah sampel minimal untuk SEM adalah 100- 200, karena jumlah sampel untuk dilakukan pengolahan secara single step maka jalan keluar kedua digunakan two step. Menurut (Hair, 2009) pengujian validitas adalah pengujian untuk mengetahui kemampuan indikator-indikator suatu konstruks (variabel laten) untuk mengukur konstruks tersebut secara akurat. Ada dua hal yang dilakukan dalam pengujian validitas yaitu pemeriksaan terhadap nilai " $\mathrm{t}$ " dan pemeriksaan terhadap tingginya muatan factor standard atau $\lambda$ (standardize loading factor). Muatan factor untuk masing masing indicator terhadap variabel latennya disajikan dalam bentuk hubungan yang digambarkan dalam bentuk hubungan yang digambarkan dalam diagram path yang diperoleh dengan menjalankan program LISREL.

Setelah menjalankan program LISREL untuk tiap variabel (PROM,AFFMARK ,OKUPANSI) secara berurutan maka diketahui nilai $\mathrm{t}$ dan $\lambda$ dari indikator pada masing masing variabel laten tersebut berada di atas nilai kritis yaitu $>1,96$ untuk nilai $\mathrm{t}$ dan 0,30 untuk nilai $\lambda$. Kecuali indikator OKUPANSI 3 untuk variabel laten OKUPANSI dibawah batas kritis yaitu sebesar $-2,67$ dan 0,53 hal ini menunjukkan bahwa indikator indikator tiap variabel laten memenuhi kriteria sebagai indikator yang valid untuk merepresentasikan tiap variabel laten yang diwakilinya.

Pengujian reliabilitas secara langsung dari output LISREL dilakukan dengan melihat nilai $\delta$ untuk variabel exogen dan $\varepsilon$ untuk variabel endogen. Dari diagram path yang dihasilkan oleh LISREL dapat dinilai bahwa nilai measurement error tiap variabel indicator sangat rendah yaitu di bawah $<0,30$. Pengujian secara tak langsung menggunakan dua parameter yaitu construct reliability dan variance extract. Perhitungan secara lengkap dapat dilihat angkuman hasil akhir pada tabel 2 berikut ini: 
Tabel 2. Reliabilitas

\begin{tabular}{lcc}
\hline \multirow{2}{*}{$\begin{array}{r}\text { Variabel } \\
\text { laten }\end{array}$} & \multicolumn{2}{c}{ Parameter } \\
\cline { 2 - 3 } & $\begin{array}{c}\text { Construct } \\
\text { Reliability }\end{array}$ & $\begin{array}{c}\text { Variance } \\
\text { Extract }\end{array}$ \\
\hline PRO, & 0,78 & 0,81 \\
AFFMARK & 0,86 & 0,79 \\
OKUPANSI & 0,89 & 0,54 \\
\hline
\end{tabular}

Sumber: Data diolah(2018)

Dari tabel 2 diatas dapat dilihat bahwa nilai Construct Reliability tiap variabel berada di atas batas kritis yaitu > 0,5 kecuali variabel laten. Sedangkan untuk variance extracted 4 variabel laten berada di atas batas kritis juga adalah variable laten OKUPANSI (OKUPANSI) sebesar 0,78 dengan nilai Construct Reliability dan

Dari hasil pengukuran reliabilitas dengan tiga parameter variabel PROM, AFFMARK dan OKUPANSI terbukti reliabel pada tiap parameter. Variabel AFFMARK meskipun nilai measurement error sangat tinggi $(0,82)$ pada salah satu variabel manifestnya AFFMARK 3 tetapi diimbangi oleh nilai Construct Reliability dan Variance Extract yang tinggi yaitu 0,78 dan 0,81 sehingga variabel AFFMARK dan OKUPANSI terbukti reliabel ,dua parameter yaitu measurement error dan varian ectract di atas batas kritis tetapi parameter Construct
Variance Extract tidak berada di batas kritis berarti bahwa variabel indikator memiliki konsistensi pengukuran yang baik terhadap variabel laten yang diwakilinya. Sebagai bahan pembanding dengan hasil yang diperoleh jurnal acuan (Blut et al., 2018) dapat dilihat dari tabel 3 sebagai berikut:

Tabel 3. Kesesuaian Model Struktur

variabel laten $\quad R$ square

$\begin{array}{ll}\text { PROM } & 0.72\end{array}$

$\begin{array}{ll}\text { AFFMARK } & 0.82 \\ \text { OKUPANSI } & 0.83\end{array}$

sumber data diolah 2018)

Reliability lebih besar dari batas kritis $(0,82$ $>70$ sehingga tetap reliabel.

\section{Pengujian Hipotesis}

Ke lima hipotesis penelitian dituangkan ke dalam dua persamaan adalah sebagai berikut:

\section{RUMUS SUBSTRUKTUR}

NOTE: $\mathrm{R}^{2}$ for Structural Equations are Hayduk's (2006) Blocked-Error R ${ }^{2}$

Reduced Form Equations

OKUPANSI $=1.393 * \mathrm{PROM}+$ 0.480*AFFMARK, Errorvar.= 1.926, R ${ }^{2}=$ 0.920

Standerr (0.348) (0.290) 
$\begin{array}{lll}\text { Z-values } & 4.000 & 1.657 \\ \text { P-values } & 0.000 & 0.098\end{array}$

OKUPANSI $=1.049 * \mathrm{PROM}+$

$0.252 *$ AFFMARK, Errorvar. $=1.063, \mathrm{R}^{2}=$ 0.0581

Standerr (0.261) (0.163)

$$
\begin{array}{lll}
\text { Z-values } & 4.028 & 1.548 \\
\text { P-values } & 0.000 & 0.122
\end{array}
$$

Pengujian hipotesis penelitian dilakukan dengan menguji hubungan antar variabel laten seperti persamaan 1-2 dan untuk menguji hubungan antar variabel laten diperlukan Score Factor dari setiap variabel laten tersebut, perlu diperhatikan bahwa kedua model struktural 1 dan 2 diuji secara serentak. Berikut ini adalah hasil pengujian hipotesis:

H1 menyatakan Promosi hotel berpengaruh terhadap Okupansi hotel dan direpresentasikan dengan persamaan (1) hasil pengujian H1 dengan LISREL:

OKUPANSI $=0,637 *$ PROM $+0.480 *$

AFFMARK, Errorvar. $=1.926, R^{2}=0.820$

Standerr $\quad(\mathbf{0 . 5 0 3 )}$

(0.289)

(0.723)

Dengan nilai t sebesar 0,503 yang besarnya jauh di atas batas kritis maka pengaruh yang diberikan variabel PROM memberikan pengaruh sebesar 0,637 terhadap OKUPANSI terbukti signifikan
H2 menyatakan Affiliation Marketing berpengaruh terhadap Okupansi dan hipotesis kedua dinyatakan dalam persamaan hasil pengujian $\mathrm{H} 2$ dengan LISREL:

OKUPANSI $=0.583 * \mathrm{PROM}+0.237 *$

AFFMARK , Errorvar. $=0.408, \mathrm{R}^{2}=0.594$

Standerr (0.103) (0.0916)

(0.105)

Dari rumus persamaan di atas terlihat bahwa nilai t variabel 0,103 berada jauh di bawah batas kritis bahkan bernilai negatif. Nilai koefisien yaitu 0,237 dengan nilai validitas $\mathrm{R}$ square yang dimiliki tinggi yaitu 0,594 berarti nilai PROMOSI hanya perlu memberikan pengaruh sebesar 0,237 terhadap Store Enviroment karena tidak siginifikan secara statistik maka variabel laten AFFMARK dikeluarkan kemudian program LISREL dijalankan lagi. Sehingga diperoleh hasil sebagai berikut:

OKUPANSI $=0.576 * \mathrm{PROM}+0.328 *$

AFFMARK, Errorvar. $=0.408$,

$\mathrm{R}^{2}=0.594$

Standerr (0.523) (0.691) (0.411) (0.405)

Persamaan di atas mengasilkan nilai $\mathrm{t}$ dan variabel baru untuk variabel Affiliation marketing Besarnya nilai $\mathrm{t}$ melewati batas kritis yaitu 0,523 sehingga terbukti memberikan pengaruh yang siginifikan. Sedangkan koefisien yang dimiliki PROM 
turun 0,576 dari 0,583 pada persamaan mula mula menjadi 0,408 pada persamaan baru.Dengan demikian telah dibuktikan bahwa hipotesis $\mathrm{H} 2$ terpenuhi (terbukti).

Hipotesis H3 menyatakan bahwa Promosi berpengaruh terhadap okupansi dan hipotesis H3 menyatakan bahwa AFFMARK berpengaruh terhadap penerimaan OKUPANSI. Hipotesis tersebut dinyatakan dalam persamaan (2) hasil pengujian $\mathrm{H} 3$ dan $\mathrm{h} 3 \mathrm{~b}$ dengan menggunakan LISREL:

OKUPANSI $=\quad 0.583 * \mathrm{PROM}+\quad 0.237 *$

AFFMARK , Errorvar $=0.408, \mathrm{R}^{2}=0.594$

Standerr (0.103) (0.0916) (0.0311) (0.105)

Persamaan di atas menunjukkan bahwa variabel AFFMARK tidak signifikan secara statistik karena nilai $\mathrm{t}$ yang dimiliki masih sangat kecil yaitu 0,105 Variabel OKUPANSI tidak memiliki nilai $\mathrm{t}$ di atas nilai kritis yaitu sebesar. Tapi karena nilai t variabel PROM tidak terlalu jauh dari batas kritis > 0,50 maka untuk pengujian ulang variabel AFFMARK tetap digunakan setelah program LISREL dijalankan maka kembali hasil yang diperoleh adalah sebagai berikut:

OKUPANSI $=0.583 * \mathrm{PROM}+0.237 *$

PROM - 0.453*AFFMARK,

Errorvar. $=0.408, \mathrm{R}^{2}=0.594$

Standerr (0.603) (0.416) (0.531) (0.405)
Setelah 5 (variabel manifested) dihilangkan maka persamaan baru menunjukkan bahwa nilai $\mathrm{t}$ variabel $\mathrm{PROM}$ telah meningkat menjadi 0,531 berarti telah melewati batas kritis dan terbukti signifikan dalam mempengaruhi promosi sedangkan koefisien yang dimiliki hanya meningkat sedikit yaitu menjadi 0,453 yang berarti persepsi pengguna terhadap penggunaan Affiliation marketing meningkat dan memberikan pengaruh sebesar 0,453 terhadap penerimaan konsumen gerai meskipun besarnya $\mathrm{R}$ square <1 yang berarti model hanya menjelaskan kurang dari $1 \%$ perubahan yang terjadi tetapi pengaruh tersebut teta pada dan hubungan kedua variabel tersebut signifikan secara statistik. jadi hipotesis $\mathrm{H} 2$ diterima dan di sisi lain hipotesis $\mathrm{H} 3$ diterima meskipun tidak cukup baik tetapi tetap signifikan. Sehingga dapat diterima.

Dalam SEM ada 3 uji kesesuaian yang dilakukan yaitu: pengujian kesesuaian model secara menyeluruh: (Overall model fit), pengujian kesesuaian model pengukuran (Measurement model fit) dan pengujian kesesuain model structural (Structural model fit). Pengujian kesesuaian model pengukuran telah dilakukan pada bagian sebelumnya.Karena berkaitan dengan Validitas dan Reliabilitas. Dengan 
menjalankan program LISREL untuk menguji kesesuain model maka dihasilkan bentuk akhir diagram Structural model fit hubungan antar variabel laten secara keseluruhan seperti pada gambar berikut ini:

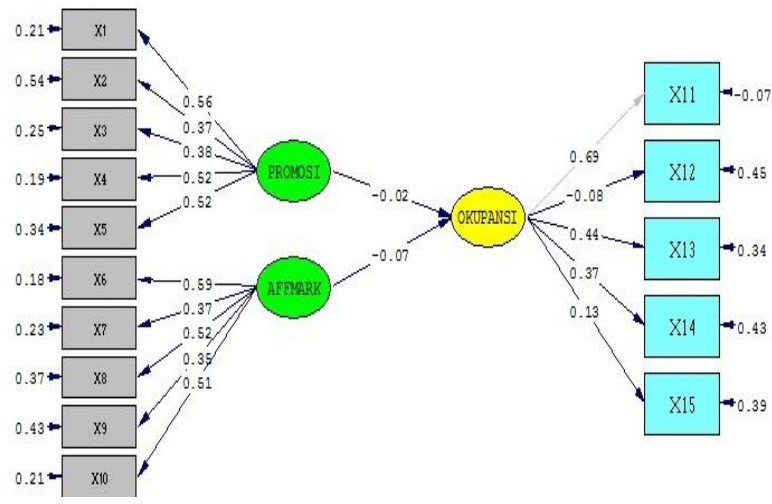

\section{Gambar 2 Structural Overall Model Fit}

Pengujian atas kesesuaian model keseluruhan akan dilakukan menggunakan indicator Godness of fit indices (GFI), GFI dipilih karena merupakan parameter (indicator) yang umum digunakan dalam menguji kesesuaian model keseluruhan selain itu sebagai pembanding juga digunakan Normed fit index dan Comparative fit index (NFI) yang didapatkan langsung dari output LISREL, besarnya nilai masing masing akan disajikan dalam tabel di bawah ini:

Tabel 4. Godness Of Fit

\begin{tabular}{lc} 
Overall model fit untuk: & NILAI \\
\hline DEGREES OF FREEDOM & 98 \\
NCP & 847,6
\end{tabular}

RMSEA

0,208

ECVI

NFI

0,443

CFI

0,463

GFI

0,720

AGFI 0,612

sumber: data diolah (2019)

Secara keseluruhan hasil pengujian model keseluruhan berada di atas nilai 0,80 kecuali pada model pengukuran variabel laten AFFMARK terhadap OKUPANSI indikator $\mathrm{GFI}=0,720$ tetapi masih diimbangi dengan nilai $\mathrm{NFI}=0,443$ dan $\mathrm{CFI}=0,463$ kesesuain model keseluruhan (overall model fit). Secara keseluruhan model yang dispesifikasi memiliki tingkat kesesuain dengan variabel manifest dan variabel laten yang mendasarinya. Menunjukkan bahwa model yang diusulkan mempunyai tingkat kesesuaian menyeluruh cukup bagus kecuali untuk hubungan variabel manifes terhadap laten variabel PROM, tetapi menurut Ghozali, (2011) nilai GFI dan NFI di atas $>0,70$ sudah cukup tinggi. Dengan demikian model struktur yang dispesifikasikan memiliki tingkat kesesuaian yang cukup tinggi

Indikator dari kesesuaian model struktur yang diajukan sama seperti dalam model path yaitu $\mathrm{R}$ square dari keseluruhan hipotesis menghasilkan 2 persamaan berarti ada 2 model struktural yang diajukan. Tetapi pada pengujian hipotesis model ke 2 
direduksi sehingga model struktural yang layak untuk melanjutkan pengujian kesesuain model adalah sebagai berikut:

\section{Rumus persamaan substruktur 1}

OKUPANSI=1.393*PROM+0.480*AFFM

RK, Errorvar. $=1.926, \mathrm{R}^{2}=0.920$ Standerr

(0.290) Rumus persamaan

substruktur 2

OKUPANSI $=1.049 * \mathrm{PROM}+0.252 *$

AFFMARK, Errorvar. $=1.063, \mathrm{R}^{2}=0.0581$

Standerr (0.261)

\section{KESIMPULAN}

Berdasarkan hasil pengujian menunjukkan bahwa promosi hotel non jaringan dan affiliasi bisnis dari agen travel online memainkan peranan penting dalam proses penilaian penjualan kamar hotel. Pihak hotel dan online travel berafiliasi secara terpusat dimana lebih cenderung memiliki tugas lebih komplek daripada pihak internal hotel.meskipun dalam hubungan bisnis pihak online travel lebih banyak memiliki keuntungan dari program afiliasi yang telah berjalan. Sampai saat ini hasil menunjukkan bahwa model bisnis afiliasi memiliki efek kuat terkait dengan masa depan industri perhotelan di masa mendatang.

\section{Saran}

Penelitian ini memiliki beberapa keterbatasan yang mungkin mempengaruhi hasil penelitian yang ingin dicapai antara lain: keterbatasan jumlah responden sehingga data tidak dapat diuji secara serentak (single step) meskipun hasil analisis yang dihasilkan akan sama tetapi diagram path yang dihasilkan tidak akan digambarkan keseluruhan model yang terdiri dari model pengukuran dan model struktural (3) keterbatasan yang melekat pada data yang diperoleh melalui kuesioner, karena perbedaan persepsi penulis dengan responden penelitian. Untuk penelitian ke depan diharapkan menggunakan metode kualitatif misalnya study kasus dengan menggunakan "depth interview" agar lebih mendalam dalam mengungkap "kotak hitam" permasalahan terkait dengan afiliasi program antara online travel dan hotel non jaringan. Keterbatasan ini menawarkan implikasi teoritis dan praktis terkait dengan afilasi bisnis dan konstribusi bukti empiris terbaru untuk memprediksi pemahaman hubungan antara pihak hotel non jaringan dengan online travel untuk perkembangan pemasaran dan persaingan bisnis yang kondusif di masa mendatang 


\section{DAFTAR PUSTAKA}

Ashley, C., Ligas, M., \& Chaudhuri, A. (2010). Can Hedonic Store Environments Help Retailers Overcome Low Store Accessibility? The Journal of Marketing Theory and Practice, 18(3), 249-262. https://doi.org/10.2753/MTP10696679180303

Blut, M., Teller, C., \& Floh, A. (2018). Testing Retail Marketing-Mix Effects on Patronage: A Meta-Analysis. Journal of Retailing. https://doi.org/10.1016/j.jretai.2018.03. 001

Brutu, M., \& Mihai, D. (2012). IDENTIFYING KEY TRENDS OF DIRECT SALES IN THE EUROPEAN UNION. Annals of the University of Petroşani Economics, 12(1), 15-24.

Carroll, J., \& Takayama, S. (2014). A hierarchical agency model of deposit insurance. Annals of Finance, 10(2), 267-290.

https://doi.org/10.1007/s10436-0130240-7

Chandra, A., Chao, C.-A., \& Astolpho, E. C. (2014). Business incubators in Brazil: does affiliation matter? International Journal of Entrepreneurship and Small Business, 23(4), 436-455. https://doi.org/10.1504/IJESB.2014.06 5678

Content Marketing Institute \& Direct Marketing Association (DMA) UK. (2015). Content Marketing in the UK 2015: Benchmarks, Budgets, And Trends. Content Marketing Report.
De Pelsmacker, P., van Tilburg, S., \& Holthof, C. (2018). Digital marketing strategies, online reviews and hotel performance. International Journal of Hospitality Management, 72(December 2017), 47-55. https://doi.org/10.1016/j.ijhm.2018.01. 003

Decker, W. H., Calo, T. J., \& Weer, C. H. (2012). Affiliation motivation and interest in entrepreneurial careers. Journal of Managerial Psychology, 27(3), 302-320. https://doi.org/10.1108/0268394121120 5835

Eapen, A., Jihye, Y. E. O., \& George, R. (2017). Business group affiliation and FDI spillovers. In 2017 Annual Meeting of the Academy of Management, AOM 2017 (Vol. 2017-Augus). https://doi.org/10.5465/ambpp.2017.16 5

Ehtiyar, R., \& Yildiz, M. (2012). Frustration: A Comparison of Chain Hotel and Independent Hotel Employees. Tourism Analysis, 17(2), 225-231.

https://doi.org/10.3727/108354212X13 330406380175

Ghozali, I. (2011). Moderated Structural Equation Modeling. In Model persamaan struktural. Konsep dan aplikasi dengan program AMOS 19.0 (pp. 180-183).

Goldstein, L. A. (2014). The FTC's "Operation Failed Resolutions": A Behind-the-Scenes Look. Response: Multi - Channel Direct Advertising, 22(5), 48. 
Hair, J. (2009). Multivariate Data Analysis. Faculty Publications.

Johnson, J. P. (2017). The agency model and MFN clauses. Review of Economic Studies, $\quad$ 84(3), 1151-1185. https://doi.org/10.1093/restud/rdx007

Kim, W. G., Lim, H., \& Brymer, R. A. (2015). The effectiveness of managing social media on hotel performance. International Journal of Hospitality Management, 44, 165-171. https://doi.org/10.1016/j.ijhm.2014.10. 014

Koeppelb, P. (2016). Marketing Mix Modeling: The Future Is Now. Response: Multi - Channel Direct Advertising, 24(7), 54.

Kotler Philip. (2016). "Branding: From Purpose to Beneficence" - Philip Kotler.

Kumar, P. (2016). Store decision criteria and patronage behaviour of retail consumers. International Journal of Management Research and Review, 6(12), 1692-1703.
Kurniawan, A., Loekito, L., \& Solimun, S. (2016). Power Of Test Path Analysis and Partial Least Square Analysis. CAUCHY; Vol 4, No 3 (2016): CAUCHYDO - 10.18860/ca.v4i3.3593 , 4(3), 112-114.

Murphy, W. F. J. (2010). IT Enabled InHome Direct Selling Presentations. In AMCIS 2010 Proceedings (p. 223).

Oppenheim, M. (2018). Millennials don't need living rooms, says top architect.

Shepter, J. (2015). ANOMALY THE AGENCY MODEL, REBOOTED. Communication Arts, 57(4), 54-61.

Telci, E. E. (2013). High shopping mall patronage: Is there a dark side? Quality and Quantity, 47(5), 2517-2528. https://doi.org/10.1007/s11135-0129668-5

Tendai, M., \& Crispen, C. (2009). In-store shopping environment and impulsive buying. African Journal of Marketing Management, $\quad 1(4), \quad 102-1$ 
